\title{
Determinants of urban-rural differentials of antenatal care utilization in Nigeria'
}

\author{
Blessing I. Babalola \\ Department of Demography and Social Statistics, \\ Federal University Oye-Ekiti, Ekiti State, Nigeria \\ And Demography and Population Studies Programme, Wits, South Africa \\ blessing.babalola@fuoye.edu.ng \\ +234- 8143509656
}

\begin{abstract}
Demographic and public health studies have indicated urban-rural differences in the utilization of antenatal care services. However, factors accounting for the urban-rural differentials in Antenatal Care use are unknown. The study used the 2008 Nigeria Demographic and Health Survey (NDHS) to examine the factors associated with the urban-rural differentials in antenatal care utilization in Nigeria. The logistic regression analysis revealed an urban rural differential in the utilization of antenatal care in Nigeria. It was revealed that rural women were less likely to use antenatal care than urban women $(O . R=0.53, C . I=0.48-0.59)$. Other determinants of antenatal care utilization in Nigeria include age, region, women educational level, religion, distance to health facility, partner's educational level, employment status, number of living children and wealth status. This study recommends that public health intervention programs and government efforts should be targeted at addressing these determinants of urban-rural differentials of antenatal care use in Nigeria in order to increase antenatal care use and consequently reduce maternal, neonatal and child mortality in Nigeria
\end{abstract}

Keywords: Urban-rural differentials, antenatal care utilization, Demographic, and Public health

\section{Résumé}

Études démographiques et sanitaires et publiques ont montré des différences urbain-rural dans l'utilisation des services de soins prénatals. Cependant, facteurs qui expliquent les différences urbain-rural dans l'utilisation soins prénatals sont inconnus. L'étude a utilisé l'Enquête Démographique et de Santé du Nigeria 2008 ( enquête démographique et sanitaire ) d'examiner les facteurs associés aux différences urbain-rural dans l'utilisation des soins prénatals au Nigeria . L'analyse de régression logistique a révélé un écart urbain-rural dans l'utilisation des soins prénatals au Nigeria. Il a été révélé que les femmes rurales étaient moins susceptibles de recevoir des soins prénatals que les femmes urbaines $(O R=0,53, I C=0,48$ à 0,59). D'autres déterminants de l'utilisation des soins prénatals au Nigeria incluent l'âge, la région, le niveau d'éducation des femmes, la religion, la distance à l'établissement de santé, le niveau d'instruction du partenaire, le statut d'emploi , le nombre d'enfants vivant et l'état de la richesse. Cette étude recommande que les programmes d'intervention en santé publique et les efforts du gouvernement devraient être ciblées sur ces déterminants des écarts ville-campagne de l'utilisation des soins prénatals au Nigeria afin d'augmenter l'utilisation des soins prénatals et par conséquent réduire la mortalité néonatale et infantile au Nigeria.

Mots clés: Les écarts ville-campagne , l'utilisation des soins prénatals , démographiques et de la santé publique

\footnotetext{
${ }^{1}$ This work was extracted from the author's Master's thesis submitted for the partial fulfilment of the award of Master's degree in Demography and Population Studies, School of Public Health and Social Sciences, University of the Witwatersrand, Johannesburg, South Africa.
} 


\section{Introduction}

Also, as Nigeria experience an increased population growth and urbanization the maternal health care facilities available in the urban area becomes more competitive and then creates a health need in the urban residence of Nigeria (Helen 1991). Nigeria is experiencing a dynamic shift of people from the rural area to the urban area which is expected to cause an improvement in the maternal and neonatal outcome in Nigeria (Bankole et al. 2009). We would expect that moving to the urban area should improve the health service utilization of pregnant women in the urban areas due to the better health services in the urban settlements than the rural settlement of Nigeria (Dairo and Owoyokun 2010). But contrary to expectation, increased urban population in Nigeria poses a challenge on the maternal health facility as health facilities became insufficient for the growing population (Helen 199I). In addition, misdirection of health funds to the urban area to the expense of the rural area creates a major urban-rural disparity in health care delivery to the detriment of the rural area with higher population (Marcellyn and Babatunji, 20I2).

Hence, this study would utilize the Nigeria Demographic and Health Survey (NDHS) to examine the socio-economic, demographic and cultural factors that are associated with the urban-rural differences in antenatal care utilization in Nigeria. The major objective of this study was to examine the urban-rural determinants of the urban-rural differentials in Antenatal Care Utilization in Nigeria. This is further divided into two specific objectives, which are (I) to describe the distribution of antenatal care utilization among the rural and urban women in Nigeria and (2) to determine the factors associated with urban-rural differential in Antenatal Care (ANC) use.

\section{Literature review and theoretical framework}

Studies have been done in developing countries that showed the differences in antenatal care utilization between rural and urban residents. Majority of the studies revealed more odds of antenatal care use among the urban women than the rural women. A study done in Sudan on the antenatal care use among women of reproductive age found that there was more utilization of routine antenatal health care services and application of $\mathrm{TT}$ - vaccination among the urban women compared to the women in the rural areas. Other factors such as higher quality of care, shorter walk-time to health facility and mother's education were significant determinants of routine antenatal care use (lbnouf et al (2007). Rahman et al. 2008 revealed in his study on the rural urban differentials of utilization of antenatal health-care services in Bangladesh that urban women received antenatal care and had antenatal visits more than rural women. It was also revealed in his study that many of the urban women relative to few rural women who received antenatal care had their blood pressure and weight checked. Mother's education, children ever born, wealth index, permission to go to hospitals or health centres from husband, source of drinking water, region and partner's education were significant determinants of receiving antenatal care. Similarly, in Nigeria this trend was established as more use of antenatal care was experienced in the urban area than the rural areas (Dairo and Owoyokun 2010).

However, the differences in patterns of antenatal care use by residence and wealth status across countries in sub-Saharan Africa could be as a result of variation in the quality of health system across these different developing countries of the world. According to Monica et al. (2003) the urban poor may be more disadvantaged in allocation and utilization of antenatal services than rural residents, especially in a country that has good health system.

Contrary to what other findings showed, Elizabeth Eggleston (2000) also supported the finding that there was no association between urban residence and more use of antenatal care compared to rural residence revealing no difference in antenatal care utilization across residence. This could be because of good health system in Ecuador (Monica et al. 2003). Elizabeth Eggleston (2000) revealed that urban residence was not associated with receiving prenatal care. The 1994 Demographic and Maternal Health Survey data was used to examine the relationship between unintended pregnancy, both unwanted and mistimed and several dimensions of prenatal care use among Ecuador Women. Findings from the study show that urban residence has no association with receiving prenatal care, but those women in the urban settlement had a higher odd of starting antenatal visit in the first trimester and receive adequate number of visits than the rural women.

Furthermore, previous studies done in Nigeria that addressed determinants of antenatal care utilization pattern could not infer conclusions to the general population. Most studies discussed elaborately on the determinants of utilization of antenatal 
care or the pattern of use of antenatal care in a specific state, region or locality. Only few studies considered the determinants of the pattern of antenatal care use at the national level (Okafor, 1991; Nwakoby 1994; Osubor et al. 2006). This limited the abilities of most studies to give a representative policy and programme recommendation for Nigeria.

The above limitations make it imperative for this study to be done so as to establish the determinants of the differentials in the pattern of utilization of antenatal care services within and between rural and urban residences that will be useful for representative health decisions on Nigerian population.

The theoretical framework for this study is the Andersen's behavioural model (2005). This model was developed to explain factors that determine the use of health services in United States of America. It examined the influence of individual and health system factors on the pattern of health service use. The framework theorized the following variables that influence the health seeking decision:

i. Predispose factors: these are factors that prompt people towards health service utilization. They include age, sex, marital status, family size, social status, education and race.

ii. Enabling factors: these are conditions that make health service resources available to an individual. They include household or family income, urban-rural character, health insurance, and health service availability.

iii. Illness level: this is a perception of the necessity for a health service. This according to Andersen is the most powerful predictor of utilization. Because even though an individual was predisposed and he has the means to seek health facility, if he has no need for it, then he would not seek health care (Andersen and Newman 2005).

\section{Data and methods}

The 2008 Nigeria Demographic and Health Survey (NDHS) was used for the analysis of this study. Women of reproductive age (15-49) were interviewed in the Nigeria Demographic and Health survey sample. However, a total of 34,596 women were selected as the NDHS sample and 33,385 women responded appropriately in the survey. This showed a response rate of $96.5 \%$.
Out of the sample, 16, I78 women with one or more birth five years before the survey were eligible for this study.

\section{Variable description}

The variables for this study were adopted from the Anderson framework of 2005. This model examined the influence of individual and health system factors on the pattern of health service use. The predisposing and enabling factors of health service utilization were selected in this study leaving out the illness or need factor as there was no question on illness factor in the 2008 Nigeria Demographic and Health Survey. The predisposing factors were age, marital status which were classified under demographic variables and education, occupation, number of living children (family size), religion and distance to health facility (residential mobility) were classified under social structure variables. Enabling factors include income which was classified under family variable and region and residence were classified under community enabling factors (Andersen 2005). The dependent variable was antenatal care use. This study defined antenatal care use as women who had at least four antenatal care visits for pregnancy. This classification was based on the World Health Organization's recommendation of a new model of antenatal care for women without complicated pregnancy in developing countries, which include at least four antenatal care visits with compulsory measurement of blood pressure, testing of urine and blood tests as well as optional weight and height measurement at each visit (WHO and UNICEF, 2003; NPC and ICF Macro, 2009).

\section{Data Analysis}

Bivariate and multivariate analysis was done to meet the first and second objectives of the study respectively. A bivariate analysis was done using chi-square test while the multiple logistic regressions was used for the multivariate analysis. The multiple logistic regression equation adopted in this study was:

Logit $\left(Y_{i}\right)=\theta+\beta_{1} X_{1}+\beta_{2} X_{2}+\cdots \beta_{i} X_{i}$ Where $Y_{i}=$ dependent variable (antenatal care); ${ }^{\theta}=$ constant; $\beta_{i}=$ Co-efficient; $X_{i}=$ independent variables. (Daniel Wiechmann, 20/3). A multiple logistic regression was used because the dependent variable was binary. The association between the dependent variable (antenatal care use) and the socioeconomic and demographic variables was examined using the odds ratio at $\mathrm{P}$-value of $<0.05$ and 95 percent confi- 
dence interval. For the analysis of this research, Stata version II was mainly used.

\section{Results}

The study revealed findings from the bivariate and the multivariate analysis. This result showed the relationship between the socio-demographic variables and the dependent variable as well as established the association between them at the multivariate level of analysis.

\section{Distribution of Antenatal Care Use by Selected Demographic and Socio-economic variables:}

The percentage distribution of the socio-economic and demographic determinants of antenatal care in the rural and urban areas respectively was revealed in table I. In the rural area age, region, women education, religion, distance to health facility, current marital status, employment, number of living children, partner's education and wealth status was significantly associated with antenatal care use. Women in the age group 25-34 had the highest percentage of antenatal care use $(39.53 \%)$ and then women at age $35+(36.70)$ and women of age 15-24 (31.31\%). South-west women had the highest percentage of antenatal care use $(83.66 \%)$ followed by women in the south-east region (70.20\%), women in the south-south region $(57.69 \%)$, women in the north central region $(47.16 \%)$, women in the north east region $(26.26 \%)$ and women in the north-west region had the lowest usage of antenatal care (I3.08\%). Women's level of education revealed a positive association with the pattern of antenatal care utilization. The more women's level of education increases the higher their use of antenatal care. Rural women with primary education recorded antenatal care usage of $52.07 \%$, the antenatal care usage increased among women with secondary education $(69.59 \%)$ and even higher percentage was recorded among women who acquired higher level of education (89.29\%). Illiterate women reported the lowest use of antenatal care (18.82\%). Other Christians displayed the highest level of antenatal care use $(59.32 \%)$ followed by the Catholic $(52.56 \%)$, then other religion which include traditionalists and others $(25.45 \%)$ and Islam women (22.81\%). Distance to health facility was also a major factor determining the use of antenatal care in rural Nigeria. Highest percentage of antenatal care use was reported among the never married women (5I.17\%), followed by formerly married women $(47.03 \%)$ and then currently married women
(35.70\%). Women employment status also revealed a consistently positive relationship with antenatal care use. Number of living children and partner's level of education also revealed a significant relationship with antenatal care. Rural poor women who received antenatal care were $22.58 \%$ while rural non-poor women who received antenatal care were $62.81 \%$.

In the urban area age, region, women education, religion, distance to health facility, current marital status, employment, number of living children, partner's education and wealth status were significantly associated with antenatal care. Women in the age group 25-34 had the highest percentage of antenatal care use $(79.27 \%)$ and then women at age $35+$ (72.54\%) and women of age 15-24 (65.76\%). Women's level of education revealed a positive association with the pattern of antenatal care utilization. The more women's level of education increases the higher their use of antenatal care. Urban women with primary education recorded antenatal care usage of $73.96 \%$, the antenatal care usage increased among women with secondary education $(86.43 \%)$ and even higher percentage was recorded among women who acquired higher level of education $(\mathbf{9 4 . 7 4 \% )}$ ). Illiterate women reported the lowest use of antenatal care (49.87\%).

Other Christians displayed the highest level of antenatal care use (83.25\%) followed by the Catholics (8I.45\%), then Islam women (66.5I\%) and others which include traditionalists and others (62.75\%). Distance to health facility was also a major factor determining the use of antenatal care in urban Nigeria. Highest percentage of antenatal care use was reported among the currently married women $(75.12 \%)$, followed by formerly married women $(66.41 \%)$ and then never married urban women $(62.50 \%)$. This was different from the pattern among the rural women. Women employment status also revealed a consistently positive relationship with antenatal care use. It was revealed that employed women's percentage of antenatal care use was $78.40 \%$ and unemployed women (65.95\%). Number of living children and partners educational level was also significantly related with antenatal care utilization in the urban areas of Nigeria. About $74.54 \%$ of urban women used antenatal care. Urban poor women who received antenatal care were $44.65 \%$ while urban non-poor women who received antenatal care were $\mathbf{7 8 . 5 2 \%}$.

In the single model combining all the respondents in Nigeria, age, region, women's level of education, religion, distance to health facility, employment sta- 
tus, marital status, number of living children, partner's level of education and wealth status are signifi- cantly associated with antenatal care utilization.

Table I. Percentage distribution of women who have had more than four antenatal care visits by selected demographic and socio-economic characteristics.

\begin{tabular}{|c|c|c|c|}
\hline Variables & Rural & Urban & All \\
\hline & $\%$ & $\%$ & $\%$ \\
\hline Age & * & * & * \\
\hline $15-24$ & 31.31 & 65.76 & 38.66 \\
\hline $25-34$ & 39.53 & 79.27 & 51.09 \\
\hline $35+$ & 36.70 & 72.54 & 45.80 \\
\hline Current Marital Status & * & * & * \\
\hline Never married & 51.17 & 62.50 & 54.09 \\
\hline Married & 35.70 & 75.12 & 45.95 \\
\hline Formerly married & 47.03 & 66.41 & 52.27 \\
\hline Region & * & * & * \\
\hline North central & 47.16 & 76.21 & 54.67 \\
\hline North east & 26.26 & 58.26 & 33.29 \\
\hline North west & 13.08 & 54.80 & 19.06 \\
\hline South east & 70.20 & 79.52 & 73.90 \\
\hline South-South & 57.69 & 78.87 & 62.82 \\
\hline South west & 83.66 & 94.07 & 89.28 \\
\hline Residence & & & * \\
\hline Urban & & 74.54 & 74.54 \\
\hline Rural & 36.42 & & 36.42 \\
\hline Women Education & * & * & * \\
\hline No education & 18.82 & 49.87 & 23.27 \\
\hline Primary & 52.07 & 73.96 & 57.71 \\
\hline Secondary & 69.59 & 86.43 & 76.96 \\
\hline Higher & 89.27 & 94.74 & 92.94 \\
\hline Partner's education & * & * & * \\
\hline No education & 16.62 & 46.61 & 20.59 \\
\hline Primary & 46.72 & 73.69 & 53.24 \\
\hline Secondary & 58.84 & 83.80 & 68.11 \\
\hline Higher & 70.31 & 88.27 & 79.79 \\
\hline Religion & * & * & * \\
\hline Catholic & 52.56 & 81.45 & 61.44 \\
\hline Other Christian & 59.32 & 83.25 & 66.76 \\
\hline Islam & 22.81 & 66.51 & 32.75 \\
\hline Others & 25.45 & 62.75 & 31.21 \\
\hline Wealth Status & * & * & * \\
\hline Poor & 22.58 & 44.65 & 23.89 \\
\hline Non poor & 62.81 & 78.52 & 70.26 \\
\hline Employment & * & & \\
\hline No & 26.97 & 65.95 & 35.88 \\
\hline Yes & 41.94 & 78.40 & 52.06 \\
\hline Living Children & * & * & * \\
\hline None & 30.15 & 55.17 & 34.55 \\
\hline $\mathrm{I}-2$ & 38.69 & 78.29 & 49.54 \\
\hline $3-4$ & 36.64 & 77.70 & 47.92 \\
\hline $5+$ & 33.80 & 65.30 & 41.05 \\
\hline Distance to Health Facility & * & * & * \\
\hline Big problem & 29.18 & 66.70 & 34.30 \\
\hline Not a big problem & 42.88 & 76.64 & 54.49 \\
\hline
\end{tabular}




\section{Determinants of antenatal care utilization}

Table 2 revealed that age, region, residence, women educational level, religion, distance to health facility, partner's educational level, employment status, number of living children and wealth status were the determinants of antenatal care utilization in Nigeria.

The findings from this study revealed that women in age group 25-34 and 35+ were 1.37 and 1.40 times respectively more likely to use antenatal care than women in age group 15-24. Women in the north east, North West, south east, south-south and north central had $0.20,0.09,0.40,0.19$ and 0.26 lower odds respectively of antenatal care use than women in the south west region.

This study revealed an urban rural differential in the utilization of antenatal care in Nigeria. It was revealed that rural women were less likely to use antenatal care than urban women $(\mathrm{O} . \mathrm{R}=0.53, \mathrm{C} . \mathrm{I}=$ 0.48-0.59).

Women who had primary, secondary and tertiary education were I.8I, 2.62 and 5.34 times respectively more likely to use antenatal care than illiterate women. Other Christian women and Islam women were $\mathrm{I} .2 \mathrm{I}$ and $\mathrm{I} .24$ times respectively more likely to use antenatal care than Catholic women. Women who did not have a big problem with seeking medical help for self due to distance to health facility were more likely to use antenatal care than women who had a big problem with seeking medical help for self due to distance to health facility (O.R = I.55. $C . I=I .42-I .69)$. Women whose partner had primary, secondary and higher education were I.84, 2.03 and 2.75 times more likely to use antenatal care than women whose partners were illiterate. Employed women were more likely to use antenatal care than unemployed women (O.R=I.2I, C.I I I.II-I.32). Women who had I-2 living children were $1.6 \mathrm{I}$ times more likely to use antenatal care than women who had no living child. Non-poor women were more likely to use antenatal care than poor women (O.R= $2.28, C . I=2.07-2.50)$.

Table 2. Demographic and socio-economic determinants of Antenatal Care Use in Nigeria.

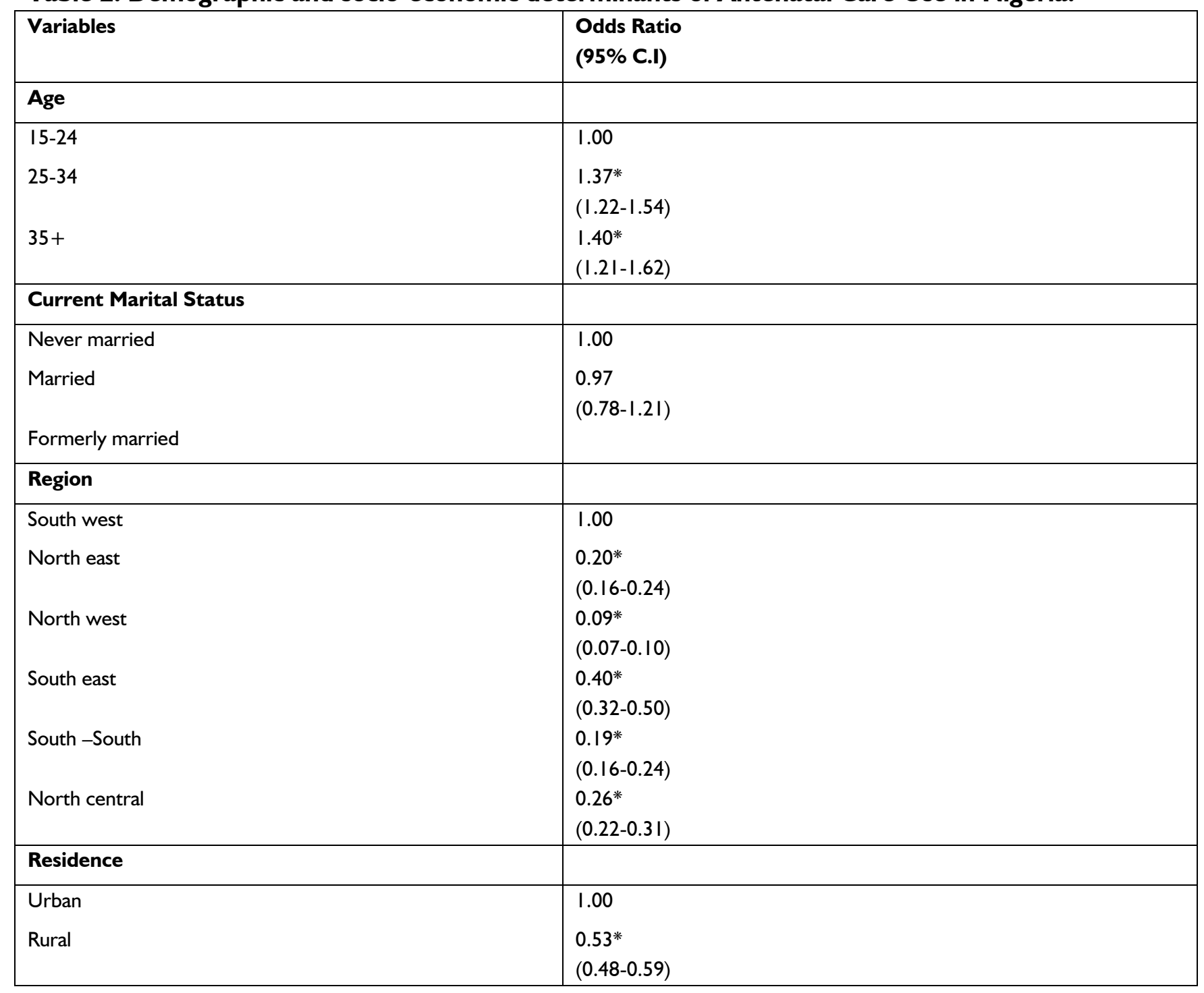


African Population Studies Vol. 28, No. 3, 2014

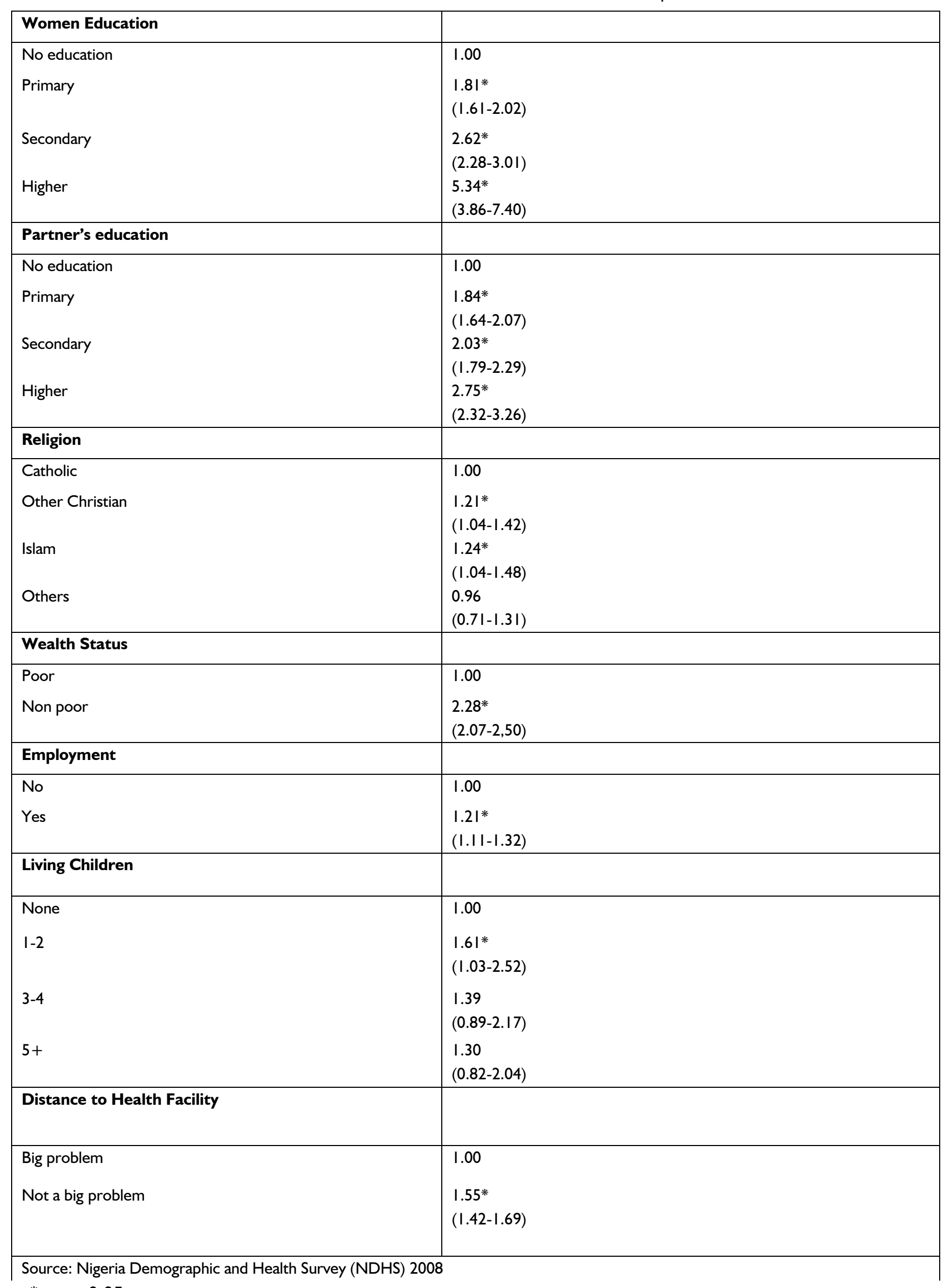

$*=p<0.05$ 


\section{Discussion}

The study objective was to identify the determinants of urban-rural differentials of antenatal care use in Nigeria. It specifically described the distribution of antenatal care utilization among the rural and urban women in Nigeria and also determined the factors that are associated with urban-rural differential in Antenatal Care (ANC) use in Nigeria.

The study revealed an urban rural differential in the utilization of antenatal care in Nigeria. The study revealed that rural women were 0.53 times less likely to use antenatal care than urban women. This agrees with the finding that urban women use antenatal care than rural women in Nigeria (Dairo and Owoyokun, 2010). It thus disagrees with the finding that urban residents had no association with the use of antenatal care (Eggleston 2000).

Furthermore, partner's and women's education was positively associated with the use of antenatal care in Nigeria. It revealed that women use of antenatal care increased as their educational attainment and that of their partners increased from primary to secondary and higher levels. Rahman et al. 2008 found a similar positive association between women and partner's education and antenatal care use. Results revealed that the higher the educational attainment of women and husbands, the more women tend to use antenatal care.

In the same vein, women whose partners were literates at tertiary, secondary and primary level of education were more likely to use antenatal care than women whose partners were illiterate. This agrees with Caldwell's opinion that men who had higher level of education have significant contribution to the decision about child care than men without any education (Caldwell 1990).

Distance to health facility was also significantly associated with antenatal care use in Nigeria. Women who had problem with reaching health facility were less likely to use antenatal care than women who did not have problem with distance to health facility. This conforms to the findings that shorter walk time to health facility was associated with antenatal care use in Sudan (lbnouf et al. 2007).

In addition, rural and urban women in the North east, North West, south east, south-south and south-west region were less likely to use antenatal care than women in the north-central region. This is similar to the finding that revealed that region is associated with antenatal care use in Bangladesh (Rahman et al. 2008).
Religion was significantly associated with antenatal care use in Nigeria. Other Christians and Islam women were more likely to use antenatal care than Catholic women. This is similar to the finding that revealed association between religion and antenatal care in Nigeria (Dairo and Owoyokun, 2010).

The study revealed that employed women were more likely to use antenatal care than unemployed women. Rahman et al. 2008 also revealed an association between employment status and antenatal care use in Bangladesh.

The number of living children was associated with antenatal care in Nigeria. This is similar to the finding that birth order was significantly associated with antenatal care use in Uttarakhand (Digambar et al. 20II).

This study adopted the 2005 Andersen theoretical framework of healthcare utilization. The framework identified variables that influence the health seeking decision as the predisposing, enabling and illness level. It revealed that the illness level was the most powerful. However, this study is limited as it was not able to measure the illness variables which the framework identifies as the most powerful determinants of health care utilization. This is because the 2008 Demographic and Health Survey used for this study did not capture the illness level variables.

\section{Conclusion}

This study revealed the determinants of antenatal care utilization in Nigeria. It revealed that age, region, residence, women educational attainment, religion, distance to health facility, partners educational attainment, employment status, number of living children and wealth status were significantly associated with antenatal care utilization in Nigeria.

However, this study recommends that public health intervention programs and government efforts should be targeted at addressing urban-rural differential in the utilization of antenatal care in $\mathrm{Ni}$ geria to increase antenatal care use and consequently reduce maternal, neonatal and child mortality. The low utilization in the rural areas of Nigeria could be addressed by influencing any of the determinants of antenatal care utilization in Nigeria. The rural urban disparity in antenatal care in Nigeria can also be solved by addressing the factors that are responsible for the low use of antenatal care in the rural areas of Nigeria as it was revealed in the total model that urban women used antenatal care than the rural women. Thus, public health intervention that would increase antenatal care use should be targeted at the 
rural residents than the urban residents. The intervention program should address improving the level of education of women and that of their partners to higher level in Nigeria. This is because women and partner's education revealed a positive relationship with women's use of antenatal care in Nigeria. This could increase their chance of becoming gainfully employed thus improving their income and then giving them the financial means to transport themselves to the far health facilities. Women and partner's education, employment, income and distance to health facility were related above because the study revealed a significant association of each of these factors with antenatal care use in Nigeria. However, these relationships may not exist in the real sense and further studies can be done to examine if there is a relationship between women education, partner's education, employment, income and distance to health facility and the use of antenatal care in Nigeria. In addition, education would also enlighten both men and women about the importance of antenatal care and would make other intervention programs by health personnel to be easily accepted by the rural residents.

Furthermore, multilevel studies should be done to address the community and state influences on antenatal care use in Nigeria. Findings from such study would help provide insights into the community and state level factors that contribute to the urban-rural differences in the utilization of antenatal care in Nigeria. In addition, qualitative studies such as focus group discussions can be used to examine the cultural factors such as beliefs systems and husband's autocratic behaviours as a result of the Nigeria's patriarchal marital system that are associated with the urban-rural differences in antenatal care utilization in Nigeria. Such studies would explore other aspect of the Andersen framework of health utilization such as community determinants, beliefs systems and illness level determinants that was not addressed in this study. A trend analysis can also be done to compare the determinants of urban-rural differentials in antenatal care use in Nigeria overtime. For instance, the determinants of the urbanrural differentials of antenatal care use in Nigeria in 1999 can be compared with the determinants of the differentials of antenatal care use in 2003 and 2008 respectively. This would revealed if there had been any changes overtime in the factors that are associated with the differentials in the use of antenatal care in the rural and urban areas of Nigeria.

In conclusion, age, region, women education, religion, distance to health facility, partner's education, occupation, number of living children, wealth and residence should be addressed by any public health intervention that seeks to promote antenatal care use in Nigeria. This is because this study revealed a significant association between antenatal care and age, region, women education, religion, distance to health facility, partner's education, occupation, number of living children, wealth and residence. However, if the recommendations given in this study were implemented there should be an improvement in the level of antenatal care use in the rural and urban areas of Nigeria as well as in Nigeria as a whole. Specifically, the urban poor and the rural poor would increase their level of antenatal care use and thus reduce the high incidence of maternal and neonatal death in Nigeria that results from poor use of antenatal care. This is because the possible solutions to the problem of low use of antenatal care in the rural compared to the urban area of Nigeria as well as among the poor in both the rural and urban Nigeria has been provided by the recommendations from this study.

\section{Acknowledgements}

This paper was extracted from the author's master's thesis obtained from the University of the Witwatersrand, Johannesburg, South Africa. The author would like to appreciate the ICF Macro for granting him the permission to use the 2008 Nigerian Demographic and Health Survey dataset.

\section{References}

Adam T, Lim S. S, Mehta S, Bhutta Z. A, Fogstad H, Mathai M, Zupan J, and Darmstadt G. L. 2005. Cost effectiveness Analysis of Strategies for Maternal and Neonatal Health in developing Countries. British Medical Journal. 33I (7525): I 107. In Tran T. K, Nguyen C. T. K, Nguyen H. D, Eriksson B, Bondjers G, Gottvall K, Ascher H and Petzold M. 20II. Urban-rural Disparities in antenatal Care Utilization: A Study of Two Cohort of Pregnant Women in Vietnam. BioMed Central Health Services Research. II: 120.

Babalola, S. and Fatusi A. 2009. Determinants of Use of Maternal Health Services in Nigeria- Looking beyond Individual and Household Factors. BioMed Central Pregnancy and Childbirth. 9 (43).

Bankole A, Sedgh G, Okonufua F, Inarhugbe C, Hussain R and Wuld D. 2009. Barriers to Safe Motherhood in Nigeria. Guttmacher Institute, Newyork. 
Dairo M. D. and Owoyokun K. E. (2010). Factors affecting the utilization of antenatal care services in Ibadan, Nigeria. Benin Journal of Postgraduate Medicine. I2(I).

Daniel Wiechmann (2013). Multivariate Analysis Technique. Retrieved from www.danielwiechmann.eu. Information retrieved 12/06/2013.

Digambar A. C. and Harihar S. 20II. Factors Influencing the Utilization of Maternal Health Care Services in Uttarakhand. Ethnographic Medicine. 5 (3): 209-216.

Eggleston E. 2000. Unintended Pregnancy and Women's Use of Prenatal Care in Ecuador. Social Science and Medicine. 51: 101 I-1018.

Fortney J. A. Editor's Comment. 2005. International Journal of Gynaecology Obstetric. 88: 179- 180. In Shiffman J and Okonofua F. E. 2007. The State of Political Priority for Safe Motherhood in Nigeria. British Journal of Obstetrics and Gynaecology. I14: 127- 133.

Fotso J. C, Ezeh A, Oronje R. 2008. Provision and use of maternal health services among urban poor women in Kenya: what do we know and what can we do? Journal of Urban Health. 85(3):428-42.

Graham W. J. 2002. Now or Never: The Case for Measuring Maternal Mortality. Lancet. 359: 70I704. In Shiffman J and Okonofua F. E. 2007. The State of Political Priority for Safe Motherhood in Nigeria. British Journal of Obstetrics and Gynaecology. I14: 127- 133.

Helen Chapin Metz, ed. 199I. Nigeria: A Country Study. Washington: GPO for the Library of the Congress.

Ibnouf A. $H$, van den Borne $H$. W and Maarse J. A. 2007. Utilization of Antenatal Care Services by Sudanese Women in their Reproductive Age. Saudi Medical Journal. 28 (5): 737-743.

lyaniwura C. A. and Yusuf Q. (2009). Utilization of Antenatal Care and delivery services in Sagamu, south western Nigeria. African Journal of Reproductive Health. I 3 (3): III-I 22.

Kabir M., lluyasu Z., Abubakar I. S., and Sani A. A. (2005).Determinants of Utilization of Antenatal Care Services in Kumbotso village, northern Nigeria. Tropical Doctor. 35(2): I I0- I I I.

Khan K. S, Wojdyla D, Say L, Gulmezoglu A. M and Van Look P. F. A. 2006. World Health Organization Analysis of Causes of Maternal Death: A Systematic Review. Lancet. 367: 1066- 1074. In Shiffman J and Okonofua F. E. 2007. The State of
Political Priority for Safe Motherhood in Nigeria. British Journal of Obstetrics and Gynaecology. 114: 127- 133.

Marcellyn B. and Babatunji O. 20I2. Nigeria's Public Health: Gains and Challenges. Equilibri.

Monica, A. M. Eliya, M. Z. Martin, B. 2003. The Inequality of Maternal Health Care in Urban subSaharan Africa in the 1990s. Population Studies. 57(3): 347-366.

National Population Commission (NPC) (Nigeria) and ORC Macro. 2009. Nigeria Demographic and Health Survey, Calverton, Maryland. NPC and ORC Macro.

Nwakoby, B.N. 1994. Use of Obstetric Services in Rural Nigeria. Journal of Reproductive and Society Health. I 14: I32-136.

Okafor, C.B. 199I. Availability and Use of Services for Maternal and Child Health Care in Rural Nigeria. International Journal of Gynaecology and Obstetrics. 34: 33I-346.

Osubor, K.M. Fatusi, A.O. Chiwuzie, J.C. 2006. Maternal Health-Seeking Behaviour and Associated Factors in a Rural Nigerian Community. Journal of Maternal and Child Health. I0: 159-169.

Rahman M, Islam R and Islam A. Z. 2008. Ruralurban Differentials of Utilization of Antenatal Health-care Services in Bangladesh. Health Policy and Development Journal. 6 (3): II I-I 25.

Shiffman J and Okonofua F. E. 2007. The State of Political Priority for Safe Motherhood in Nigeria. British Journal of Obstetrics and Gynaecology. 114: 127- 133.

Ujah I. A. O, Aisien O. A, Motihir J. T, Vanderjagt D. J, Glew R. H and Ugunu V. E. 2005. Factors Contributing to Maternal Mortality in North-central Nigeria: A Seventeen-year Review. African Journal of Reproductive Health. 9 (3): 27-40.

United Nations, 2010. Op. Cit. P. 38. In United Nations Women Watch: Information and Resources on Gender Equality and Empowerment of Women. www.un.org/facts-figures.html

Wall L. L, 1998. Dead Mothers and Injured Wives: The Social Context of Maternal Morbidity and Mortality among the Hausa of Northern Nigeria. Studies in Family Planning. 29 (4): 34I-359.

WHO and UNICEF (2003). Antenatal Care in Developing Countries: Promises, Achievements and Missed Opportunities. An analysis of Trends, Levels and Differentials: 1990-200I. Geneva, Newyork. In Tran T. K, Nguyen C. T. K, Nguyen H. D, Eriksson B, Bondjers G, Gottvall K, Ascher 
$\mathrm{H}$ and Petzold M. 20I I. Urban-rural Disparities in antenatal Care Utilization: A Study of Two Cohort of Pregnant Women in Vietnam. BioMed Central Health Services Research. II: 120.

Zanconato G, Msolomba R, Guarenti L, and Franchi M. 2006. Antenatal Care in Developing Countries: the need for a Tailored Model. Seminar on Foetal Neonatal Medicine. I I (I): I5-20. In Tran T. K, Nguyen C. T. K, Nguyen H. D, Eriksson B, Bondjers G, Gottvall K, Ascher $\mathrm{H}$ and Petzold M. 20I I. Urban-rural Disparities in antenatal Care Utilization: A Study of Two Cohort of Pregnant Women in Vietnam. BioMed Central Health Services Research. II: 120. 